\title{
XX. Short Reports from the chemical laboratory of Trinity College, Dublin
}

\section{J. Emerson-Reynolds M.D.}

To cite this article: J. Emerson-Reynolds M.D. (1878) XX. Short Reports from the chemical laboratory of Trinity College, Dublin , Philosophical Magazine Series 5, 5:29, 144-153, DOI: $10.1080 / 14786447808639400$

To link to this article: http://dx.doi.org/10.1080/14786447808639400

曲 Published online: 13 May 2009.

Submit your article to this journal $\widetilde{x}$

Џ Article views: 2

Q View related articles $\square$ 
$\{411\},\{611\},\{711\},\{10,11\}$, and $\{233\}$ were found in alternate octants only, and are consequently hemihedral. The

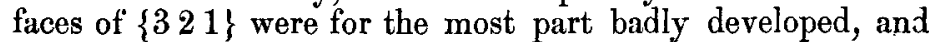
did not permit of any certain conclusion being drawn. Hessenberg found a plane of the form in each of two adjacent octants which excludes a hemihedrism with inclined faces. I believe it, from my observations, to be holohedral. A further examination of such crystals as are to be found in the various collections might possibly set the question of the hemihedrism of the mineral at rest, and would certainly be interesting.

XX. Short Reports from the Chemical Laboratory of Trinity College, Dublin. By J. Emerson-Reynolds, M.D., Professor of Chemistry, University of Dublin*.

No. 5. On the Rapid Estimation of Urea.

A DISTINGUISHED physician, who wished to make A frequent determinations of the urea daily excreted by a patient, requested me to devise a method which would enable him to make the desired estimation- $(a)$ rapidly, $(b)$ with sufficient accuracy for ordinary clinical purposes, $(c)$ with simple and easily constructed apparatus, and $(d)$ without the use of a balance or of any measuring-vessels other than the fluid-ounce and minim measures which a medical man is in the habit of employing.

This interesting practical problem was solved in the manner I shall presently describe; and the results obtained by the use of the method devised have been so satisfactory as to lead me to expect that it may be found generally useful where a high degree of accuracy is not desired.

I propose, however, before concluding this paper, to describe a less simple plan for the estiniation of urea than that just referred to, but one which is capable of affording results of greater precision.

In both the methods mentioned I take advantage of the now well-known reaction of sodic hypobromite with urea. When a strongly alkaline solution of sodic hypobromite is added to a liquid containing urea, the latter suffers rapid decomposition into water, carbonic anhydride, and pure nitrogen gas. The carbonic anhydride is not evolved as gas, but is absorbed, with formation of sodic carbonate, by the free alkali of the liquid used to effect decomposition; the nitrogen is evolved in the gaseous condition, and its bulk determined either indirectly or

* From the Scientific Proceedings of the Royal Dublin Society. Communicated by the Author. 
directly, the volume of nitrogen produced thus serving as a measure of the urea from which it was derived.

The equation which expresses the change just referred to is the following :-

$$
\begin{aligned}
& \mathrm{CO}^{\prime \prime} \mathrm{N}_{2} \mathrm{H}_{4}+3(\mathrm{NaBrO})+2(\mathrm{NaOH})=3 \mathrm{NaBr}+\mathrm{Na}_{2} \mathrm{CO}_{3}
\end{aligned}
$$

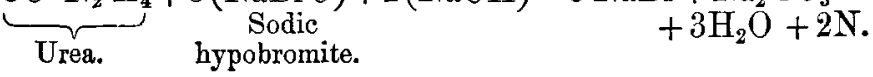

The use of calcic bypochlorite, or solution of "chloride of lime," in effecting a similar decomposition was pointed out by Dr. E. W. Davy*; and it has been recently shown by Yvon $\dagger$ that the hypochlorite used by Davy is more effective than the sodic hypochlorite, but it does not evolve the whole of the nitrogen and is irregular in its action. Knop, and after him Hüfner $\ddagger$, and many others, have shown that the sodic hypobromite is greatly to be preferred to any of the hypochlorites, as the decomposition of urea is almost complete, and progresses regularly and rapidly without the aid of heat : hence I use the hypobromite as the basis of the plan of operating now to be described, and in this respect agree with Hüfner, Russell and West, R. Apjohn, Blackly, Dupré [and with Simpson and O'Keefe $\S]$ in the methods they have proposed for ureaestimation.

The different methods devised by the above-named chemists all serve for the direct measurement of the volume of nitrogen evolved during the action of the hypobromite on urea, and involve the use of specially graduated tubes for the reception and measurement of the pure gas. My plan is essentially different, as the gas evolved, which is scarcely soluble in water $\|$, is made to displace its own volume of that liquid, and the latter is then easily measured in any ordinary vessel, such as a tall and well-graduated drachm measure.

The apparatus may be most conveniently described as consisting of two distinct parts-A, the generating-vessel (see annexed woodcut, fig. 1), and $F$ the small gas-holder, from which water is expelled by the nitrogen entering from $A$.

Gas-generating Vessel.-This is an ordinary two-ounce widemouthed bottle, fitted with a good india-rubber cork pierced with three holes. Through one of these holes the gas-delivery tube $\mathbf{E}$ passes, and through another the small piece of bent

* Journal of the Royal Dublin Society, and Phil. Mag. [IV.] vol. vii. p. 403.

$\dagger$ Journal de Pharmacie et de Chimie, [4] vol. xxiv.

I Journal für praktische Chemie, [2] vol. iii. p. 1.

Published since this paper was read.

II According to Bunsen, water dissolves only 0.01478 of its volume at the mean temperature and pressure (Bunsen's 'Gasometry,' p. 286).

Phil. Mag. S. 5. Vol. 5. No. 29. Feb. 1878. 
glass tube $\mathrm{C}$. The heat afforded by a spirit-lamp suffices for bending these tubes from straight pieces, and for the conversion Fig. 1.

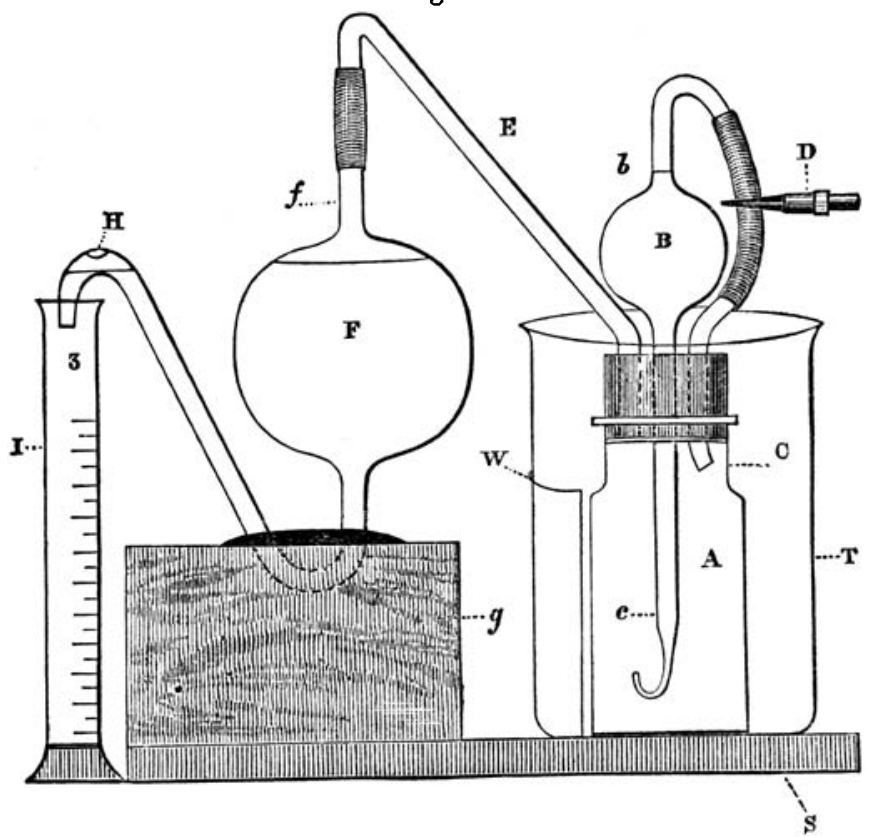

of an ordinary bulb-pipette, capable of holding rather more than one fluid-ounce, into a vessel of the form $B$.

The delivery-tabe of the pipette is first passed through the remaining hole in the cork, and the end of the tube then drawn out and recurved, as shown at $c$; the tube above $b$ is bent so far down as to admit of its being connected by means of an india-rubber tube with the outer extremity of C. At D the india-rubber tube is securely clipped by a small artery-forceps with broad jaws. When the cork carrying the tubes just described is secured in the bottle, the generating-vessel is complete. When an estimation is in progress the bottle $\mathrm{A}$ is placed in a tumbler, $\mathrm{T}$ (or beaker), containing cold water at a temperature of $52^{\circ} \mathrm{F}$., as nearly as possible.

The Gas-receiver.-This is easily constructed from a large pipette whose bulb $\mathrm{F}$ is capable of containing about three fluidounces. The tube $f$ is cut off so as to admit of being securely joined to the tube $\mathbf{E}$ of the generating-vessel by means of an india-rubber connector. The delivery-tube is then bent, as shown, and at the point $\mathrm{H}$ a little hole is made. A groove cut in a block of wood $g$ receives the bent tube of the little gas-holder, which is then easily secured in its place by any 
suitable cement-common sealing-wax, for example. Thus, with the aid of the two pipettes, cork, and tubing, which can be easily procured through a druggist for about 3s., a medical man can construct his own ureometer*.

When in use the block $g$ is secured to the board $\mathrm{S}$, on which the beaker $T$ stands held by the wire $W$.

Mode of using the Apparatus.-The vessels A and $\mathrm{F}$ are discomnected, and $\mathbf{F}$ filled with water until it overflows and the excess has ceased to drip from the tube under $H$. The cork is removed from the bottle A, and two fluid-drachms of the liquid to be tested measured off in a tall minim-measure, and then poured into $A$; one drachm of water is next used to rinse the liquid adhering to the sides of the measuring-glass into the bottle $\mathrm{A}$ : the total volume in $\mathrm{A}$ therefore should measure about three drachms $\dagger$. For a reason which will presently appear, it is desirable that no more water than one drachm should be employed. If a pipette delivering two drachms be used, a drachm of water should be added; but the pipette need not be rinsed with it. The next step is to fill the pipette $B$ with the reagent which evolves the nitrogen of the urea. For this purpose a suitable vessel (a wine-glass for example) is filled with the hypobromite liquid $¥$; the forceps $\mathrm{D}$ is removed from the india-rubber tube, but is placed close at hand, and a piece of vulcanized tubing, five or six inches long, attached to the end of the glass tube $\mathrm{C}$; suction is then applied by the mouth when the curved end $c$ of the pipette is immersed in the hypobromite. The pipette is thus easily filled by suction with the re-agent up to the mark $b$. The forceps D is next applied to the connector, as shown, before the lips are withdrawn from the india-rubber tube attached to $\mathrm{C}$; the suction tube may then be removed from $\mathrm{C}$, as the liquid is retained in B by atmospheric pressure, provided $\mathrm{D}$ pinches the tube well. Having washed the end $c$ by pouring a little water over it, the cork carrying all its apparatus is securely inserted in the bottle $\mathrm{A}$, the latter placed in the beaker $\mathrm{T}$ containing enough water to cover the cork when $\mathrm{A}$ is pressed down, and the tube $\mathrm{E}$ securely connected by the

* Messrs. Yeates \& Son, of Dublin, supply a veat form of my apparatuis ready for use.

$\dagger$ The measure used should be good, the two-drachm and two-ounce ressels agreeing with each other. The amount of reliance which can be placed upon the results depends in great part on the accuracy of the measures.

† This solution is prepared as follows:-Dissolve 4 ounces of the solid caustic soda of the shops in 10 fluid-ounces of water. When the soda has dissolved and the liquid cooled to $60^{\circ} \mathrm{F}$., add gradually 1 fiuid-ounce of bromine. The test solution is then ready for use. It should be kept in a cool place, and away from the light. 
tightly-fitting india-rubber tube with $f$. While connecting the generator and receiver a little water is necessarily expelled from the tube beyond $\mathrm{H}$; but this water is thrown away, and the $d r y$ two-ounce measure, I, then placed under the spout.

Up to this point the hypobromite has not been allowed to come into contact with the urine; but now, on removing the forceps $\mathrm{D}$, the hypobromite flows out from $c$ and rapidly mixes with the urine, the urea of which yields up its nitrogen gas with effervescence. As the gas evolved has no exit save through $\mathrm{E}$, it displaces from $\mathrm{F}$ its own volume of water, which falls into the vessel $I$, and can then be measured when no more water is expelled. The effervescence ceases after five or ten minutes, according to the temperature.

It is essential to good measurement that the pressure within the apparatus should be the same at the end as at the beginning of the experiment; in order to secure this, the simple plan is adopted of placing a wedge under the board $S$ at the end indicated, which is thus so tilted that the eye placed at a point a little below D, and looking immediately above the surface of the water in $\mathrm{F}$, can just see the bend of the tube under $\mathrm{H}$. When the pressure within and without has been thus equalized, the amount of water expelled is the measure of the nitrogen evolved in A; for we may in a test of this kind neglect the extremely minute proportion of the nitrogen which has been dissolved by the water.

When it is desired to correct for temperature and pressure by means of the usual formula, it is now necessary to disconnect $\mathbf{E}$ and $f$, and to pass the bulb of a small thermometer through $f$ into the gas over the water in $\mathrm{F}$; after a minute or so the temperature may be read off and recorded, and the barometric reading made at the same time. In ordinary clinical experiments, however, the correction for temperature may be neglected when a thermometer in the room stands near to $52^{\circ}$ F. The neighbourhood of a fire or stove must be avoided in making the estimations of urea.

In measuring the water expelled we may either read off the volume in drachms or sixths of a drachm; but since ordinary cylindrical two-ounce measures are rarely graduated to less than half-drachms, the best plan is to pour the excess over a definite number of drachms into a tall two-drachm measure, bearing in mind that every ten-minim division represents the sixth of a drachm.

I find as the results of a large number of direct experiments with a standard solution of pure urea, some of which will be given further on, that one grain of urea produces sufficient gas at a temperature of $52^{\circ} \mathrm{F}$. and a barometric pressure of $30^{\circ} 06$ 
inches to expel 64 drachms of water, the volume of liquid in the bottle A being three drachms, and the hypobromite added ten drachms.

It may be mentioned that measures of capacity need not be employed in the determinations of urea, as the water expelled may be received in any suitable vessel which has been previously weighed. At the end of the experiment the vessel and expelled water are weighed. When the estimation was made, under the conditions above named, one grain of urea was found to expel, as a mean, 365 grains of water by weight. This number is easily remembered, as it happens to be identical with the number of days in a year.

Effect of the Degree of Dilution upon the Determination of Urea.-An apparently trifling observation led me to examine the effect of dilution upon the yield of nitrogen obtainable from a constant weight of urea; and the results arrived at are stated in the Table given below.

The quantity of pure dry urea operated with in each of the following experiments was $2 \cdot 222$ grains; and the same volume (i.e. ten fluid-drachms) of a single sample of freshly prepared sodic hypobromite was added in each case. The experiments were completed within three and a half hours; and care was taken to avoid changes of temperature as much as possible : hence, while the barometer remained steady at 30.06 inches, the temperature varied within such very narrow limits (between $50^{\circ}$ and $52^{\circ}$ F.) that corrections for alterations of volume were unnecessary, as extreme accuracy in the measures of the water expelled was not attainable with the vessels advisedly employed, as I desired the results to be of such a kind as a medical man could easily obtain in his own study.

TABLE.

\begin{tabular}{|c|c|c|c|}
\hline $\begin{array}{l}\text { No. of } \\
\text { experi- } \\
\text { ment. }\end{array}$ & $\begin{array}{l}\text { Pure dry urea } \\
\text { used in } \\
\text { experiment. }\end{array}$ & $\begin{array}{l}\text { Volume of water } \\
\text { used to dissolve } \\
\text { urea in } A \text {. }\end{array}$ & $\begin{array}{l}\text { Volume of } \\
\text { water expelled } \\
\text { from } \mathrm{F} \text {. }\end{array}$ \\
\hline $\begin{array}{r}1 . \\
2 . \\
3 . \\
4 . \\
5 . \\
6 . \\
7 . \\
8 . \\
9 . \\
10 . \\
11 . \\
12 . \\
13 .\end{array}$ & $\begin{array}{c}2 \cdot 222 \text { grains. } \\
\text { ", } \\
\text { ", } \\
\text { ", } \\
\text { " } \\
" \\
" \\
" \\
"\end{array}$ & 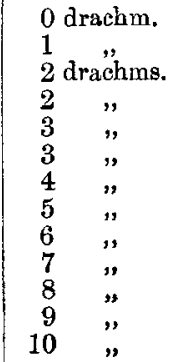 & 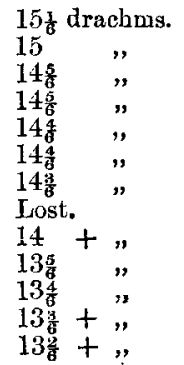 \\
\hline
\end{tabular}


The weight of urea taken for each experiment is capable of affording a volume of moist nitrogen gas at the temperature and pressure above stated, which would expel 154 drachms of water. The maximum volume obtained from that weight of pure dry urea was $15 \frac{1}{6} \mathrm{drachms}$. Thus there is a minimum loss of 3.3 per cent. The maximum observed loss in the foregoing experiments amounted to 14.9 per cent., and occurred in the experiment in which the above-named weight of urea was dissolved in ten drachms of water. The loss within the above limits is tolerably regular, as the volume of nitrogen is diminished by $\frac{1}{6}$ of a drachm (nearly) for each drachm of water added to the urea in the decomposition-vessel $\mathrm{A}$.

The loss of nitrogen referred to is, doubtless, due in part to solution of the gas; but it is chiefly attributable to the regular diminution of the strength of the oxidizing agent used, the hypobromite solution, and to a corresponding increase in the extent of secondary changes which are known to occur in the diluted liquids, and which involve a loss of gaseous nitrogen. Much of the error arising from the latter cause is avoided by adopting the plan of employing a constant volume of liquid; hence the recommendations already made that two drachms of urine should be measured into the bottle $A$, and the measure rinsed out with not more than one drachm of water. The total bulk of liquid in A ought then to measure as nearly as possible three drachms. Even when the sample to be tested is measured with a pipette, it is well to add one drachm of water from an ordinary measure in order to bring up the total volume of liquid to the amount recommended.

When the simple precautions are taken which I have already mentioned, the little apparatus described in this paper will enable a considerable number of estimations of urea to be made with rapidity, and with sufficient accuracy for ordinary clinical purposes. When very precise determinations are required, Liebig's process must be resorted to, as all the methods in which hypobromites or hypochlorites are employed are liable to the errors pointed out above ; the accuracy of the results is also affected by the action of the reagent used on uric and hippuric acids, creatinine, and other nitrogenized compounds. On the other hand, when we desire to ascertain the total amount of nitrogen excreted by the kidneys, it is necessary to resort to the precise method of estimation which I communicated to the Surgical Society of Ireland*.

* Vide Medical Press and Circular, May 13th, 1874, p. 402. 
Estimation of Urea by direct Determination of the Nitrogen Gas evolved by Sodic Hypobromite.

The piece of apparatus now to be described was exhibited ata meeting of the Scientific Club in 1871 , and has proved most useful for the estimation of urea by the hypobromite method, and, with a little modification, for the estimation of carbonic acid in carbonates, and for other similar purposes. I shall only refer at present to its use in ureometry. In this apparatus the nitrogen evolved is directly measured as gas under conditions which admit of very accurate determinations of volume in cubic centimetres.

The apparatus is shown in section in fig. 2. The stand A supports a tall glass cylinder B. Through the large india-rubber cork which closes the lower opening of the cylinder the U-tube $c$ is passed, great care being taken to avoid breaking the small Tconnector $c$. The onter limb of the U-tube is provided with a glass tap T. The limb within the tall glass cylinder is sufficiently wide to contain 150 cub. centims. in the expanded portion, which, in my
Fig. 2.

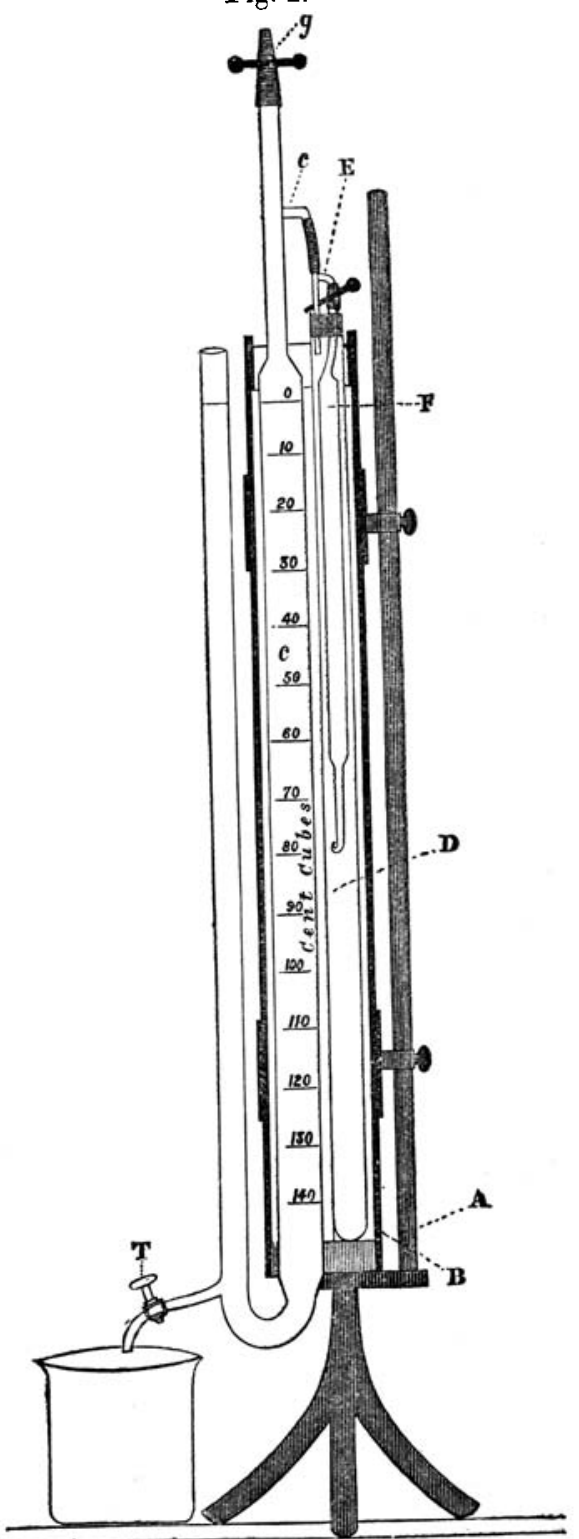


apparatus measures 60 centims. in length. The graduation cannot be conveniently carried beyond fifths of a cubic centimetre. At the point shown an india-rubber tube $g$ is attached, which can be closed at will either by a good clip or by a stopper of glass rod. The glass side-tube $c$ serves to connect the measuring-apparatus in the manner shown with the generating-vessel D, which is a long and wide glass tube placed within the cylinder. The glass I'tube $\mathrm{E}$ is connected by means of rubber tubing with $c$, while one limb passes through the india-rubber cork of $\mathrm{D}$, and the other is connected by another piece of rubber tubing with the fine tube of the long pipette $\mathrm{F}$ (of about 20 cubic centims. capacity) which projects through the cork. This connexion must be sufficiently long to admit of the clip being applied as shown.

The large glass cylinder $\mathrm{B}$ is filled with water in order to maintain a steady temperature, the value of which can be known by means of a thermometer immersed in the water.

A determination is made with this apparatus in the following way:- Having disconnected the T-tube $\mathbf{E}$ from $c$ and the clip, the generating-tube $\mathrm{D}$ is taken out of the water of the cylinder, the cork carrying the pipette, \&c. withdrawn, and then 5 cubic centimetres of the urea solntion introduced into the tube $D$. Before replacing the cork the pipette $\mathrm{F}$ is filled with hypobromite solution by suction above $\mathrm{E}$, while the small glass tube opening on the underside of the cork is closed by a finger; the clip is then applied. The exterior of the pipette is now washed with a little water, and the cork, with the apparatus attached, is then replaced in position, the tube D again immersed in the water of the large cylinder, and the connexion between $\mathrm{E}$ and $c$ securely made. Before making the connexion the water in the graduated tube should stand at the zero of the scale; but after making the joint the pressure within the apparatus is usually greater than that without. As the air in the tube $D$ cools down to the temperature of the surrounding water, contraction takes place; but should the water not return to the zero, equilibrium is at once restored by opening the fine india-rubber tube $g$ for a few seconds, and then closing in such a manner as to prevent any possible escape of gas.

The hypobromite is brought into contact with the urea solution by removing the clip from the india-rubber tube connected with the pipette; the reagent then falls from a considerable height and mixes thoroughly with the liquid at the bottom of the tube D. Nitrogen is evolved and displaces water from $c$, the water being maintained at the same level in both limbs of the U-tube by allowing the liquid displaced to run off by means of the tap T. When the evolution of gas has ceased. 
the water-level is adjusted by means of the tap, and the volume of gas produced in the reaction then read off on the graduated tube $c$; the temperature of the water in the cylinder $B$ is then ascertained, as well as the height of the barometer at the time. From the data thus obtained, the volume of dry nitrogen at $0^{\circ} \mathrm{C}$. and 760 millims. can be easily calculated by the usual formula.

XXI. Notices respecting New Books.

Experimental Researches in Pure, Applied, and Physical Chemistry. By E. Frankland, Ph.D., D.C.L., F.R.S. London: John Van Voorst. 1877.

$D^{R}$. FRANKLAND has laid his chemical brethren under a great obligation by the publication of his researches in a collected and classified form. That obligation may be best repaid by the determined efforts of other chemists to explore those fields of knowledge which have been left untrodden by the author of the work now before us.

The researches of the South-Kensington Professor extend over a period of about thirty years; they are arranged in three sections -Pure, Applied, and Physical Chemistry.

In the division of Pure Chemistry, Dr. Frankland has rendered himself famous by his researches upou the Alcoholic radicals, Organo-metallic bodies, and Synthesis of the Acids of the Lactic, Acrylic, and Acetic series. At the time when the earlier of these investigations appeared, the chemistry of the Carbon compounds was in a state of confusion: many facts had been collected, but little breath of life had been breathed into these dry bones. Laurent and Gerhardt had scarcely made known the results of the application of their brilliant classificatory powers to the facts of organic Chemistry. The theory of radicals had indeed been advanced by Liebig and Kane; but the unscientific use of hypotheses concerning the nature of organic compounds was yet, for the most part, dominant. Berzelius and his dualistic theory were masters of the field. In terms of this theory, Berzelius viewed Acetic Acid as a conjugated compound containing the groups $\mathrm{C}_{2} \mathrm{H}_{3}$ and $\mathrm{C}_{2} \mathrm{O}_{3}$ (old notation). It is worthy of remark that the exceedingly imperfect and one-sided theory of Berzelius, as applied in the above-cited case, should have furnished an idea which, when worked out by Dr. Frankland in his researches upon the "Conversion of Cyanogen into Oxatyl," led to results of much importance in advancing the more coinplete and more probable theories of modern Chemistry. The Radical theory of Liebig found great support by the publication of Frankland's memoirs upon the "Isolation of the Alcoholic Radicals." In attempting to isolate the radicals Methyl, Ethyl, and Amyl by the action of metals upon the iodides of these bodies, Frankland obtained results which he then regarded, and which, judging from the introductory remarks in the present volume, he seems still inclined to regard, as proof of the actual isolation of these radicals. Frankland pointed out the analogy between Hydrogen and the radicals of the Alcohols; and, if the molecular formula of Hydrogen be $\mathrm{H}_{2}$, he 